\title{
Preparation and Characterization of Poly $(\beta$-Amino Ester) Capsules for Slow Release of Bioactive Material
}

\author{
Fahima Mosad Helaly, Mona Samir Hashem \\ Polymers and Pigments Department, National Research Center, Giza, Egypt \\ Email: monasamir80@yahoo.com
}

Received February 22, 2013; revised March 22, 2013; accepted March 30, 2013

Copyright (C) 2013 Fahima Mosad Helaly, Mona Samir Hashem. This is an open access article distributed under the Creative Commons Attribution License, which permits unrestricted use, distribution, and reproduction in any medium, provided the original work is properly cited.

\begin{abstract}
Network structures from poly( $\beta$-amino ester) (PAE) were synthesized for applying as drug delivery matrix via a simplified addition polymerization method. It can hold an active organic compound (drug) that has an effect as antitumor activity in order to control its release. PAE was prepared from piperazine and 1,4-butandiol diacrylate with different molar ratios. The active compound was mixed with the prepared polymer while warming for 15 minutes to obtain the capsule product. The resulting polymer structures and the surface morphology of the PAE capsules before and after encapsulation with the active drug were characterized by FT-IR and SEM, respectively. Swelling and degradation behavior of PAE were studied. The characterization showed that, the obtained network structure of PAE depends on the molar ratio between the reactants. The optimum ratio of the reactants was found to be 1:1. Therefore, stable and white product as well as good holding capability for drug produced. The SEM studies illustrate good dispersion and holding properties of the drug into the network structure of the prepared polymer. In vitro, the release results of the drug from the PAE capsules indicated that the capsules were able to give sustained release of drug in DMF up to 10 days at $25^{\circ} \mathrm{C}$.
\end{abstract}

Keywords: Poly( $\beta$-Amino Ester); Addition Polymerization; Drug Delivery; Swelling; Degradation; In Vitro Release

\section{Introduction}

Many therapeutic anticancer drugs, while pharmacologically effective in cancer treatment, are limited in their clinical applications by serious toxicities. The development of anticancer drug carriers can improve therapeutic efficacy and reduce unwanted side effects [1]. Cationic copolymers have been developed based on poly(amino urethan) and poly(amido-amine) $[2,3]$.

$\operatorname{Poly}(\beta$-amino ester) (PAE) is a cationic polymer which is easily synthesized by addition polymerization and known to be readily biodegradable and of low cytotoxicity [4]. PAE acts as a hydrophilic block because of the ionization of tertiary amine at a relatively low $\mathrm{pH}$ and becomes a hydrophobic block because of deionization of tertiary amine at a higher $\mathrm{pH}$ [5]. PAE has been widely investigated for gene delivery [6] and cancer cytoplasmic drug release [7].

The present work aims to synthesize and characterize network structure of $\operatorname{poly}(\beta$-amino ester) applying as carrier for an active organic compound (antitumor drug) and fabricate into capsule form, also, to evaluate the efficiency of the prepared polymer holding drug for control release drug through the release rate of the active compound.

\section{Materials and Methods}

\subsection{Materials}

Piperazine and 1,4-butanediol diacrylate were purchased from Sigma-Aldrich. N-hexane, dimethyl formamide (DMF), dimethyl sulfoxide (DMSO), dichloro methane (DCM), ethyl acetate (EtOAc) and tetrahydrofuran (THF) were obtained from Aldrich. 7-(2-methoxyphenyl)-3-methyl-5-thioxo-5,6-dihydro[1,2,4]-triazolo[4,3-c]pyrimidine8 -carbonitrile (MTPC) which has been prepared and evaluated as anticancer bioactive drug [8]. It has molecular formula as follows.

\subsection{Methods}

\subsubsection{Synthesis of $\operatorname{Poly}(\boldsymbol{\beta}$-Amino Ester)}

The polymer synthesis was carried out according to Michael addition polymerization: from 1,4-butandiol diacrylate and piperazine. Each dissolved in tetrahydrofuran (THF). The reaction was carried out in round bottom 
three neck flask containing reflux condenser and thermometer at $50^{\circ} \mathrm{C}$ for 48 hours. So, the 1,4-butandiol diacrylate solution was introduced into the flask and the piperazine solution was added dropwise to the acrylate solution. Different mol ratios of the reactant were used as indicated $(1: 1),(2.3: 1)$ and $(1: 2.3)$. After the reaction was completed, the poly $\beta$-amino ester was obtained through precipitation in $\mathrm{n}$-hexan [9].

\subsubsection{Swelling Response of $\operatorname{Poly}(\boldsymbol{\beta}$-Amino Ester)}

The swelling properties of the resulting polymer were evaluated using dimethyl sulfoxide (DMSO), dichloro methane (DCM) and ethyl acetate (EtOAc) at room temperature. The initial mass of the polymer capsules were recorded $\left(W_{i}\right)$, and then, the capsules were placed in the corresponding solvents at room temperature. The capsules were removed from the solvents at a given time, and their masses were recorded in swollen state $\left(W_{s}\right)$. The same solvents were used throughout the swelling studies [10]. The dynamic weight change of the polymer with respect to time was calculated by the following equation:

$$
\text { Weight change }(\%)=\frac{W_{s}-W_{i}}{W_{i}} \times 100
$$

where $W_{s}$ and $W_{i}$ are the weight of the polymer in the swollen state and the initial weight of the polymer, respectively.

\subsubsection{In Vitro Degradation of PAE}

The in vitro degradation of the PAE hydrogel was examined using the mass loss method. Briefly, $4 \mathrm{~mL}$ vials contained $100 \mathrm{mg}$ of PAE at $\mathrm{pH} 7.4$ were incubated at $37^{\circ} \mathrm{C}$ in $15 \mathrm{~min}$ to form a gel. Subsequently, $3 \mathrm{~mL}$ of phosphate-buffered saline (PBS, $\mathrm{pH} 7.4$ ) was added, and the sample vials were incubated at $37^{\circ} \mathrm{C}$. The PBS in the vials was replaced with fresh PBS every day. At a predetermined time, the samples were collected, freeze-dried and the residue weight checked. The remaining weight of the degraded gels was calculated from the ratio of lyophilized degraded gels to the initial gels [11]. The experiments were performed in triplicate.

\subsubsection{Drug Encapsulated Polymeric Capsules}

The polymeric latex $(1 \mathrm{~g})$ was mixed with $(0.1 \mathrm{~g})$ of the active prepared drug (organic compound which had promising effect as antitumor) [8]. The drug polymer capsules were left to equilibrate for 24 hours at room temperature.

\subsubsection{Determination of the Drug Encapsulation Efficiency}

The encapsulation efficiency (EE) was measured after extracting the drug from the prepared polymeric capsules [12]. $100 \mathrm{mg}$ of MTPC-loaded polymeric capsules were subjected to disperse in $100 \mathrm{~mL}$ DMF and stirred for 30 $\min$ at $37^{\circ} \mathrm{C}$ to ensure the complete extraction of the drug. The mixture was stirred magnetically at $1000 \mathrm{rpm}$ for $4 \mathrm{~h}$. The mixture solutions increased to $250 \mathrm{~mL}$ volumes with DMF. After centrifuging at $4000 \mathrm{rpm}$ for $30 \mathrm{~min}$, these solutions were diluted and analyzed by a UV-Vis spectrophotometer at $360 \mathrm{~nm}$. All experiments were done in triplicate. The EE of drug is calculated and expressed as the following equation:

$$
\mathrm{EE}(\%)=\frac{\text { Practical drug loading }}{\text { Theoretical drug loading }} \times 100 \text {. }
$$

\subsubsection{Drug Release from Polymeric Capsules}

In a typical procedure to determine the in vitro release of the drug from the polymeric capsules, drug-loaded capsules prepared were immersed in $10 \mathrm{~mL}$ DMF at $37^{\circ} \mathrm{C}$ with horizontal shaking. At timed intervals, $1 \mathrm{~mL}$ of the medium was withdrawn and the same volume of fresh DMF was added to keep the total volume constant. The drug released into the fluid was determined from the measurement of absorbance at $360 \mathrm{~nm}$ analyzed by a UV-Vis spectrophotometer according to the standard curve and expressed as follows:

$$
\text { Drug release }(\%)=\frac{\text { released drug }}{\text { total drug }} \times 100
$$

where released drug was calculated from the drug concentration $(\mathrm{mol} / \mathrm{L})$ measured in the total solution volume and total drug was the amount loaded in each capsule. All experiments were done in triplicate.

\subsubsection{Characterization}

The characterization of the prepared polymer was carried out according to the following techniques:

1) FT-IR spectra were recorded on a FT-IR spectroscopy (Nicolet 670, range from $4000-400 \mathrm{~cm}^{-1}$, USA) using $\mathrm{KBr}$ pellets.

2) Surface morphology was visualized by scanning electron microscopy (JXA-840A Electron probe microanalyzer, JEOL, Japan) using an accelerating voltage of $30 \mathrm{KV}$ after coating with gold film using S150A Sputter Coater (Edwards, England).

The drug loading and release studies were measured using double-beam Spectrophotometer (Shimadzu UV2401 PC, Japan).

\section{Results and Discussions}

\subsection{Poly( $\beta$-Amino Ester) Synthesis and Characterization}

This section focused on the synthesis and characterization of $\operatorname{poly}(\beta$-amino ester). The addition polymerization process for Piperazine and 1,4-butanediol diacrylate via low temperature resulted in a complex-structured of PAE 
as described in Scheme 1. Different molar ratios of the reactants were used to give the highlight on the suitable controlling product that gives optimum specific properties for use as polymer carrier drugs.

Table 1 summarizes the physical properties of the resulted products of the polymer forms of PAE according to the monomer ratios. It is shown from the visual inspection that, the color of the products changed from pale yellow to yellow and the state of the polymer product changed from gel to brittle solid based on the molar ratio of the reactants. So, it is able to control the properties and molecular weight of the prepared polymer through change molar ratio of the reactants. Therefore, it is necessary for the polymer to have specific properties to ease the holding of the investigated active compound and consequently, useful for applying as drug delivery system for increasing the ability to release the active ingredient for long period of time.

The prepared polymer was characterized using FT-IR and SEM studies.

\subsection{FT-IR Characterization}

Figure 1 indicated the IR spectra of the prepared $\operatorname{Poly}(\beta$ amino ester). It is shown that, the characteristic peaks for the functional groups are found at $1259 \mathrm{~cm}^{-1}$ for piperazine group, $3445 \mathrm{~cm}^{-1}$ for $\mathrm{OH}$ group and $1637 \mathrm{~cm}^{-1}$ for acrylate group. These results confirmed the presence of PAE.
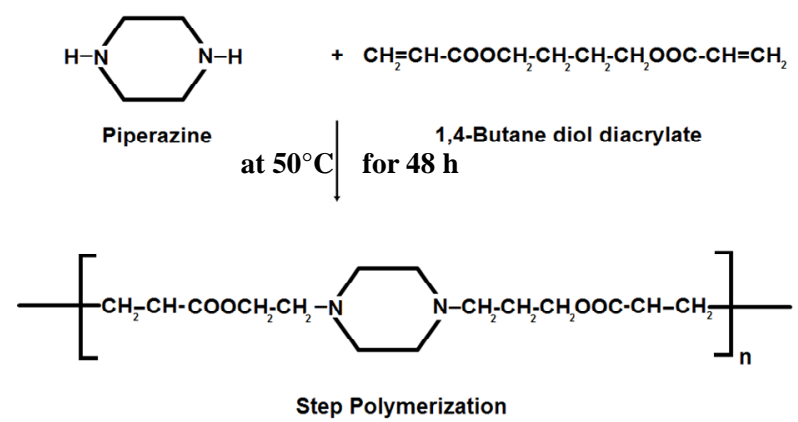

Scheme 1. The reactant materials, conditions and the produced product of PAE.

Table 1. The molar ratios of the reactant materials and the specification of the obtained PAE.

\begin{tabular}{|c|c|c|c|c|}
\hline \multirow{2}{*}{ No. } & \multicolumn{2}{|c|}{ Reactant materials (mole) } & \multirow{2}{*}{$\begin{array}{l}\text { Mole } \\
\text { ratio }\end{array}$} & \multirow{2}{*}{$\begin{array}{l}\text { Specification of } \\
\text { polymer product }\end{array}$} \\
\hline & Piperazine & $\begin{array}{l}\text { 1,4-butanediol } \\
\text { diacrylate }\end{array}$ & & \\
\hline 1 & 0.5 & 0.5 & $1: 1$ & Pale yellow gel \\
\hline 2 & 0.7 & 0.3 & $2.3: 1$ & $\begin{array}{c}\text { Pale yellow viscous } \\
\text { solution }\end{array}$ \\
\hline 3 & 0.3 & 0.7 & $1: 2.3$ & $\begin{array}{l}\text { Yellow brittle } \\
\text { crushed solid }\end{array}$ \\
\hline
\end{tabular}

\subsection{SEM Characterization}

It is interesting to characterize the surface texture of the investigated $\operatorname{poly}(\beta$-amino ester) before and after carrying the drug to illustrate what happens to the distribution and spreading of the drug through the surface of the test specimen. Scanning electron microscope is a valuable technique for this study. Figure 2 illustrates the micrograph of the surface texture of the prepared products.

Figure 2(a) shows a good homogeneity for the structure texture, no grooves as blistering on the surface of the investigated polymer before carried drug. After carrying the drug, the micrograph in Figure 2(b) shows good dispersion and penetration of the drug through the surface texture of the polymer.

\subsection{Swelling Response of PAE}

The swelling behavior is a very important property for drug delivery system because it has a great influence on the drug release behavior [13]. The swelling study of PAE polymer capsules was conducted in three different solvents: DMSO, DCM and EtOAc at room temperature in order to study the polymer solvent interaction. It has been observed from Figure 3 that for all the systems in DCM and EtOAc the maximum swelling is achieved in approximately $2 \mathrm{~h}$. However, in case of DMSO as solvent, the maximum swelling was observed in approximately $6 \mathrm{~h}$. This dependence of the extent of swelling on the polymer/solvent system could be explained by polymer solvent interaction parameter, which is an indicator of polymer miscibility in the solvent. These results are confirmed with that obtained by Biswal et al. [10].

\subsection{In Vitro Degradation of PAE}

The degradability of the PAE polymer capsules was monitored by examining the weight loss of capsules according to the incubation time in $\mathrm{PBS}\left(\mathrm{pH} \mathrm{7.4)}\right.$ at $37^{\circ} \mathrm{C}$, as shown in Figure 4. The PAE polymer showed relatively fast degradation in vitro, with $60 \%$ and $40 \%$ weight remaining after 10 and 14 days, respectively. The results of biodegradation studies in $\mathrm{PBS}\left(\mathrm{pH} \mathrm{7.4)}\right.$ ) at $37^{\circ} \mathrm{C}$ were consistent with a polymer that underwent hydrolytic surface degradation as a function of time. The faster degradation profile, as compared to other synthetic polyesters, was due to the ease of surface hydrolysis by water molecules [14].

\subsection{Encapsulation and Controlled Release of MTPC from PAE}

The percentage of encapsulation efficiency of the MTPCloaded PAE was 100\%.

The potential application of PAE polymer for drug delivery was assessed by examining the in vitro release of 


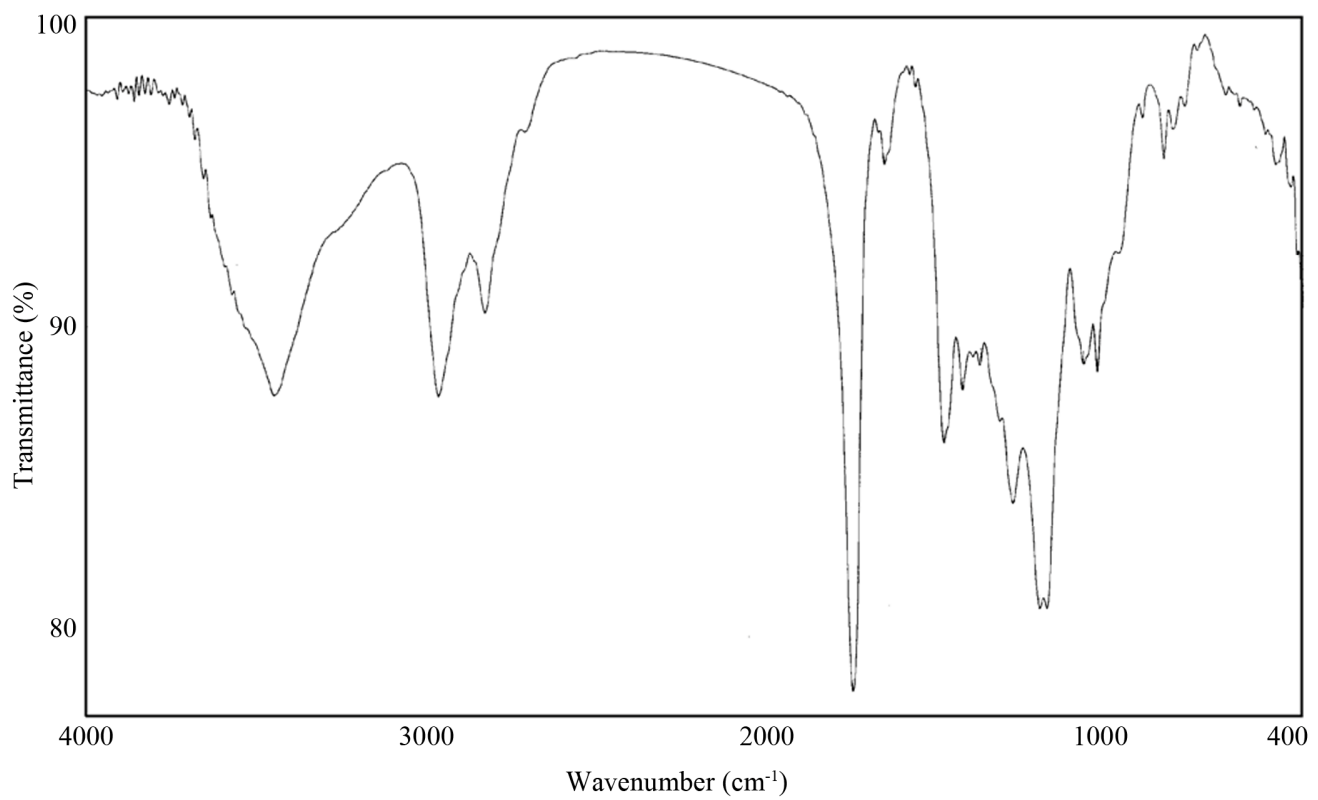

Figure 1. FT-IR of PEA.
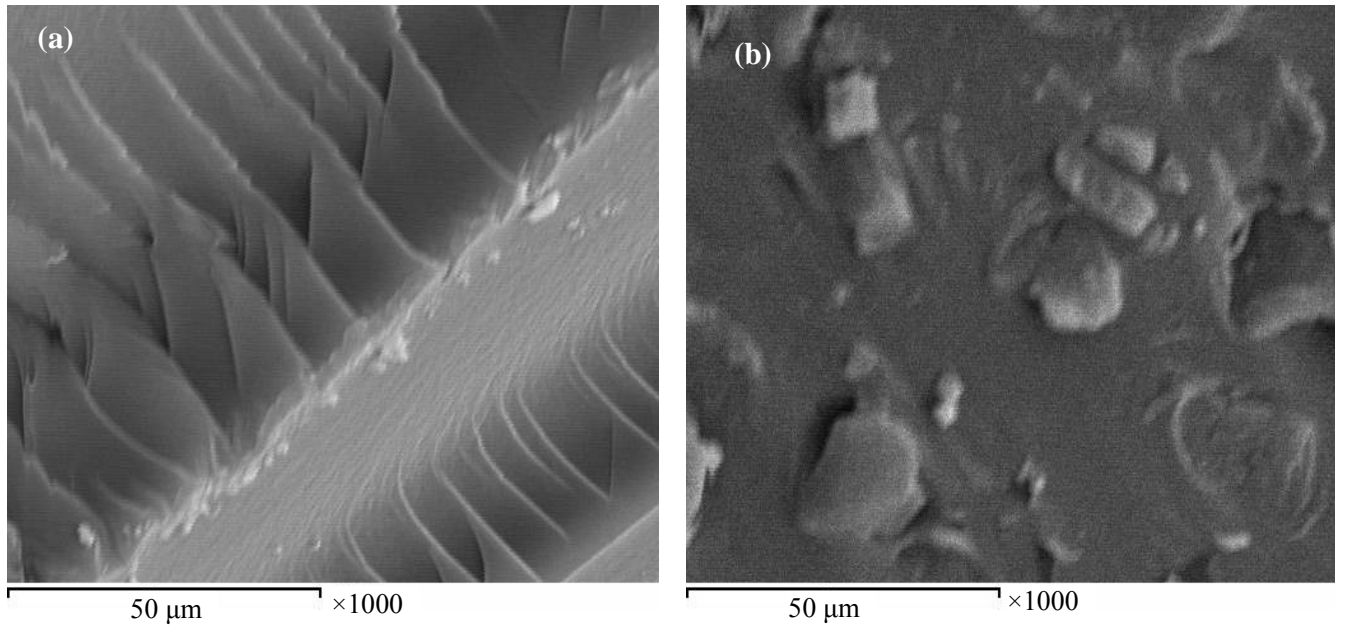

Figure 2. SEM of PEA (a) before and (b) after loading with the drug.

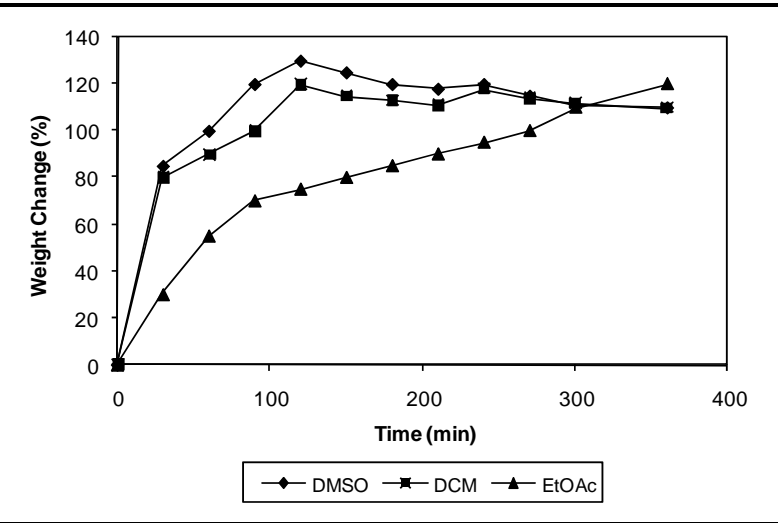

Figure 3. Swelling response of PAE in DMSO, DCM and EtOAc.

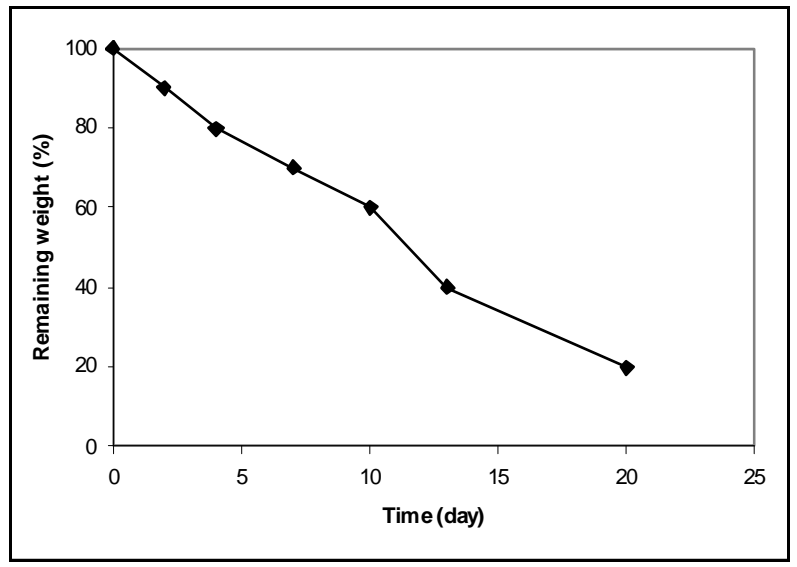

Figure 4. In vitro degradation of PAE. 

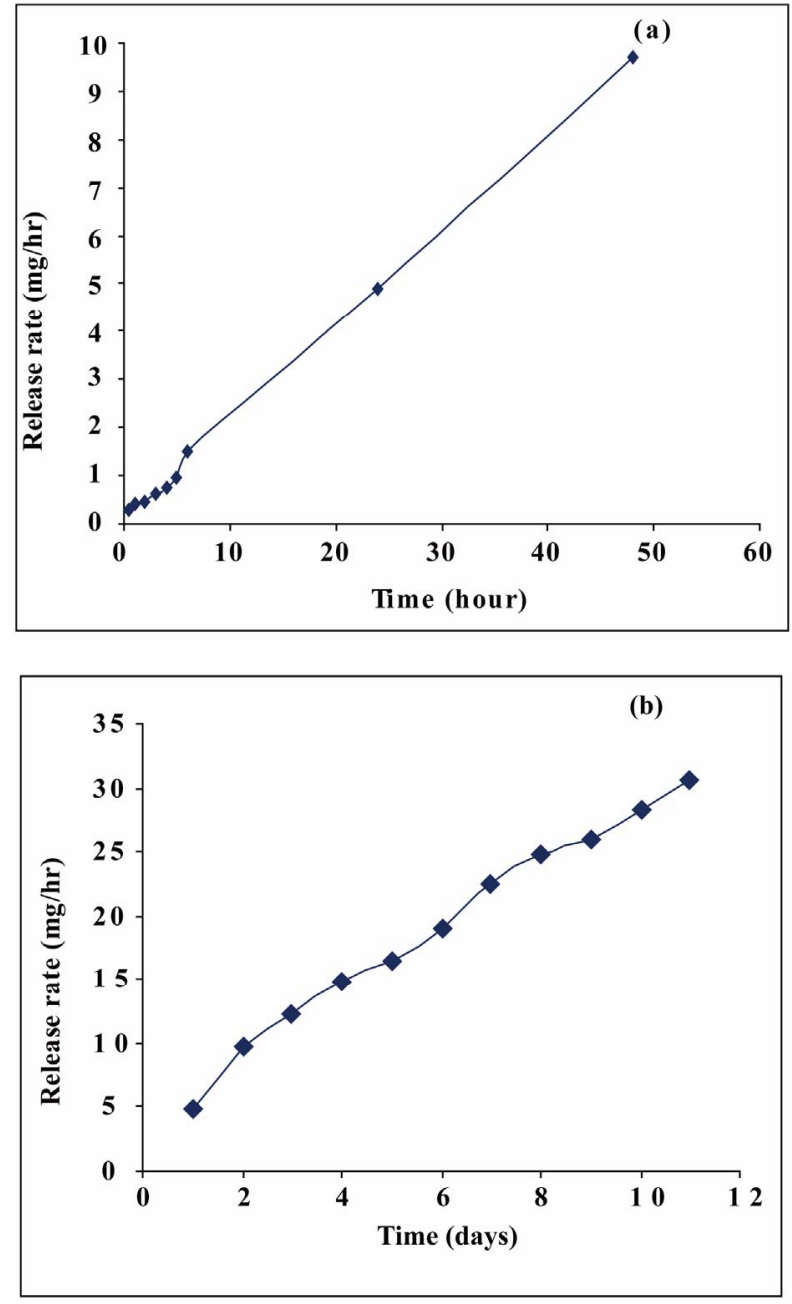

Figure 5. The release rate of MPTC from PAE in DMF.

MTPC, an anticancer drug, from this polymer. The release rate of MTPC from PAE was evaluated spectrophotometerically at $360 \mathrm{~nm}$ within the first $48 \mathrm{~h}$ as shown in Figure 5(a). It was found that PAE polymer released the anticancer drug in a slow manner. Furthermore, the release profiles showed that MTPC had undergone controlled release from PAE polymer for more than 10 days, as shown in Figure 5(b).

\section{Conclusion}

Network structure of poly( $\beta$-amino ester) was synthesized from piperazine and 1,4-butanediol diacrylate by Michael addition polymerization. The prepared polymer carried drug is characterized by FT-IR and SEM. The release of the drug was extended to over 10 days in DMF at $25^{\circ} \mathrm{C}$.

\section{REFERENCES}

[1] J. Koa, K. Park, Y. Kim, M. S. Kim, J. K. Han, K. Kim, R.
Park, I. Kim, H. K. Song, D. S. Lee and I. C. Kwon, “Tumoral Acidic Extracellular pH Targeting of pH-Responsive MPEG-Poly $(\beta$-Amino Ester) Block Copolymer Micelles for Cancer Therapy," Journal of Controlled Release, Vol. 123, No. 2, 2007, pp. 109-115. doi:10.1016/i.jconrel.2007.07.012

[2] J. Elisseeff and J. Hubbell, "Synthesis and Characterization of Photo-Cross-Linked Polymers Based on Poly(Llactic acid-co-L-aspartic acid)," Macromolecules, Vol. 30, No. 7, 1997, pp. 2182-2184. doi:10.1021/ma961411w

[3] D. K. Han and J. Humbll, "Lactide-Based Poly(ethylene Glycol) Polymer Networks for Scaffolds in Tissue Engineering," Macromolecules, Vol. 29, No. 15, 1996, pp. 5233-5235. doi:10.1021/ma9601070

[4] S. A. Meenach, C. G. Otu, K. W. Anderson and J. Z. Hilt, "Controlled Synergistic Delivery of Paclitaxel and Heat from $\operatorname{Poly}(\beta$-Amino Ester)/Iron Oxide-Based Hydrogel Nanocomposites," International Journal of Pharmaceutics, Vol. 427, No. 10, 2012, pp. 177-184. doi:10.1016/j.ijpharm.2012.01.052

[5] D. M. Lynn and R. Langer, "Degradable Poly(BetaAmino Esters): Synthesis, Characterization, and Self-Assembly with Plasmid DNA", Journal of American Chemical Society, Vol. 122, No. 44, 2000, pp. 10761-10768. doi:10.1021/ja0015388

[6] H. J. Kim, M. S. Kwon, J. S. Choi, B. H. Kim, J. K. Yoon, K. Kim and J. Park, "Synthesis and Characterization of Poly (Amino Ester) for Slow Biodegradable Gene Delivery Vector," Bioorganic \& Medicinal Chemistry, Vol. 15, No. 4, 2007, pp. 1708-1715. doi:10.1016/j.bmc.2006.12.004

[7] Y. Shen, H. Tang, Y. Zhan, E. A. V. Kirk and W. J. Murdoch, "Degradable Poly( $\beta$-Amino Ester) Nanoparticles for Cancer Cytoplasmic Drug Delivery," Nanomedicine: Nanotechnology, Biology, and Medicine, Vol. 5, No. 2, 2009, pp. 192-201. doi:10.1016/j.nano.2008.09.003

[8] O. A. Fathalla, I. F. Zeid, M. E. Haiba, A. M. Soliman, S. I. Abd-Elmoez and W.S. El-Serwy, "Synthesis, Antibacterial and Anticancer Evaluation of Some Pyrimidine Derivatives," World Journal of Chemistry, Vol. 4, No. 2, 2009, pp. 127-132. http://idosi.org/wjc/4(2)09/7.pdf

[9] M. Sang and D. Sang, "Modulation of $\operatorname{Poly}(\beta$-Amino Ester) $\mathrm{pH}-$ Sensitive Polymers by Molecular Weight Controll," Journal of macromolecular Research, Vol. 13, No. 2, 2005, pp. 147-151. doi:10.1007/BF03219029

[10] D. Biswal, P. P. Wattamwar, T. D. Dziubla and J. Z. Hilt, "A Single-Step Polymerization Method for $\operatorname{Poly}(\beta$-Amino Ester) Biodegradable Hydrogels," Polymer, Vol. 52, No. 26, 2011 , pp. 5985-5992. doi:10.1016/j.polymer.2011.10.058

[11] T. Huynh, M. K. Nguyen and D. S. Lee, "Biodegradable $\mathrm{pH} /$ Temperature-Sensitive Oligo( $\beta$-Amino Ester Urethane) Hydrogels for Controlled Release of Doxorubicin," Acta Biomaterialia, Vol. 7, No. 8, 2011, pp. 3123-3130. doi:10.1016/j.actbio.2011.05.004

[12] S. Hu, H. Ma, X. Li, H. Yang and A. Wang, "pH-Sensitive Sodium Alginate/Poly(vinyl Alcohol) Hydrogel Beads Prepared by Combined $\mathrm{Ca}^{2+}$ Crosslinking and Freeze-Thawing Cycles for Controlled Release of Diclofenac 
Sodium," International Journal of Biological Macromolecules, Vol. 46, No. 5, 2010, pp. 517-523. doi:10.1016/i.ijbiomac.2010.03.004

[13] Q. Wang, X. L. Xie, X. W. Zhang, J. P. Zhang and A. Q. Wang, "Preparation and Swelling Properties of $\mathrm{pH}-$ Sensitive Composite Hydrogel Beads Based on Chitosan$g$-Poly (Acrylic Acid)/Vermiculite and Sodium Alginate for Diclofenac Controlled Release," International Journal of Biological Macromolecules, Vol. 46, No. 3, 2010, pp.
356-362. doi:10.1016/j.ijbiomac.2010.01.009

[14] A. Potineni, D. M. Lynn, R. Langer and M. M. Amiji, "Poly(ethylene Oxide)-Modified Poly( $\beta$-Amino Ester) Nanoparticles as a $\mathrm{pH}$-Sensitive Biodegradable System for Paclitaxel Delivery," Journal of Controlled Release, Vol. 86, No. 2-3, 2003, pp. 223-234.

doi:10.1016/S0168-3659(02)00374-7 